\title{
Burnout or Compassion Fatigue? A Comparative Concept Analysis for Nurses Caring for Patients in High-Stakes Environments
}

\author{
Franklin Wynn, PhD(c), MSN, RN, CNE, OCN \\ The University of Texas at Tyler, Tyler, Texas
}

\begin{abstract}
Burnout and compassion fatigue are two distinct concepts experienced by nurses caring for patients in high-stakes environments. Nurses often do not recognize which concept they are experiencing due to the similarities and interchangeable use of these terms in literature. Nurses in high-stakes settings need to have these concepts further explored as they impact their physical and psychological health. This comparative concept analysis examines these terms using Walker and Avant methodology. Defining attributes, antecedents, consequences, empirical referents, and constructed cases are discussed. This analysis adds to the nursing knowledge needed to support nurses in achieving optimal occupational health and well-being.
\end{abstract}

Keywords: burnout; compassion fatigue; concept analysis; nursing

Burnout and compassion fatigue are a growing concern for nurses working in high-stakes environments, such as emergency rooms, critical care, and oncology units, where patients have potential for life-threatening health outcomes (Al-Majid, Carlson, Kiyohara, Faith, \& Rakovski, 2018; Hinderer et al., 2014; Rushton, Batcheller, Schroeder, \& Donohue, 2015; Wentzel \& Brysiewicz, 2018). Nurses in these settings must frequently make urgent critical decisions, resolve ethical dilemmas, and participate in extensive multidisciplinary collaborations (Guveli et al., 2015; Ko \& Kiser-Larson, 2016). At the same time, they also witness the extensive trauma and suffering of their patients and experience grief and bereavement as patients succumb to death (Harris \& Griffin, 2015; Lee, Laurenson, \& Whitfield, 2012; Potter, Deshields,
\& Rodriguez, 2013; Sullivan et al., 2019). As these investments are physically and emotionally demanding, nurses in high-stakes environments are at an increased risk for burnout and compassion fatigue.

Although burnout is a term that nurses are often more familiar with, many find it confusing to distinguish from compassion fatigue (Potter, Deshields, Berger et al., 2013; Potter et al., 2013; Villani et al., 2013). This could be related to the common use of both terms interchangeably in the literature, often to describe one congruent experience (Al-Majid et al., 2018; Jenkins \& Warren, 2012; Lynch \& Lobo, 2012). The distinction of these concepts is further complicated by the reporting of similar outcomes such as stress, exhaustion, mood swings, difficulty with managing personal 
conflicts, detachment in caregiving, and poor job satisfaction (Guveli et al., 2015; Jenkins \& Warren, 2012; Lee, Kuo, Chien, \& Wang, 2016).

\section{Purpose}

The purpose of this article is to provide an in-depth analysis of the concepts of burnout and compassion fatigue in the context of high-stakes nursing environments. An analysis contrasting these concepts was not found in the literature; however, a comparison of this type is needed to provide clarity of these terms that distinguishes them as two separate phenomena. Moreover, understanding how these concepts agree and how they are different will help nurses cope with caring for high-stakes patients and support them in achieving optimal occupational health and well-being.

The methodology of Walker and Avant (2011) was used to analyze the related concepts of burnout and compassion fatigue. This multi-step process is expected to define, clarify, and operationalize the ill-explained aspects of phenomena into constructs that can be understood and utilized in practice (Walker \& Avant, 2011). The analysis began with an exhaustive search to identify the uses and definitions of burnout and compassion fatigue in the literature. From these articles, critical attributes and antecedents have been identified so that each term can be recognized within a context. To further assist in the recognition and proper use of the terms burnout and compassion fatigue, consequences for each term are discussed to expand on how they can be experienced. Measurement of each concept is described as empirical referents. The information gleaned from the analysis for each concept is then compared and contrasted to allow for the synthesis of these concepts and correct distinction of them within constructed cases (model and contrary). After this synthesized comparison, the reader is expected to be able to discern what each concept is and is not; particularly in the context of healthcare and high-stakes nursing environments.

\section{Method}

Literature was searched using Academic Search Complete, CINAHL Complete, Health Source Nursing Academic Edition, and PsycINFO databases. Keywords for the search included burnout, compassion fatigue, concept analysis, antecedents, attributes, empirical referents, and consequences for each respective concept. The search was limited to the English language and the years
1974 through 2019. After retrieving the initial yield from the combined searches, abstracts were reviewed for applicability to high-stakes environments or caring for high-stakes patients. A total of 52 articles were included in this comparative concept analysis.

\section{Uses and Definitions of Burnout and Compassion Fatigue}

\section{Burnout}

Freudenberger (1974) first introduced burnout in literature as a term that was used to describe a "loss of charisma" for work among healthcare workers. This loss of charisma was attributed to workers feeling worn out, or tired, in performing their work duties (Freudenberger, 1974). In 1981, Maslach and Jackson further expanded the concept of burnout by describing it as a combination of symptoms they coined burnout syndrome, which are feelings of increased emotional exhaustion, depersonalization, and lack of personal accomplishments. This revised definition provided more clarity to what a "loss of charisma" may look like in individuals experiencing burnout.

The concept of burnout has been found commonly discussed among disciplines with high stress and performance expectations, such as nursing, law enforcement, social work, education, and athletics (Akhrem \& Gazdowska, 2016; Finney, Stergiopoulos, Hensel, Bonato, \& Dewa, 2013; Klinoff, Van Hasselt, Black, Masias, \& Couwels, 2018; Savas, Bozgeyik, \& Eser, 2014). Table 1 shows that descriptors such as an exhaustive, strung-out state related to meeting job demands were common across the various definitions of burnout; particularly in the nursing, law enforcement, and social work literature.

\section{Compassion Fatigue}

In 1992, Joinson first introduced the term compassion fatigue in the field of nursing and defined it as the loss of a nurse's ability to nurture their patients. However, many of the definitions observed in the literature are derived from Figley's (1995) definition; which is recognized as the most common definition of compassion fatigue. Figley defined compassion fatigue as a feeling of biological, psychological, and social exhaustion caused by prolonged exposure to compassionate stress. 
TABLE 1. Definitions of Burnout

\begin{tabular}{|c|c|}
\hline Source & Definition \\
\hline \multirow[t]{2}{*}{$\begin{array}{l}\text { Classical Definition (derived from the field of } \\
\text { Psychology) }\end{array}$} & $\begin{array}{l}\text { The loss of charisma for work attributed to feelings of being worn out, } \\
\text { or tired, in performing work duties (Freudenberger, 1974). }\end{array}$ \\
\hline & $\begin{array}{l}\text { Burnout syndrome: the increased emotional exhaustion and depersonal- } \\
\text { ization experienced from a lack of personal accomplishments (Maslach } \\
\text { \& Jackson, 1981). }\end{array}$ \\
\hline \multirow[t]{3}{*}{ Nursing } & $\begin{array}{l}\text { "A prolonged response to chronic emotional and interpersonal stressors } \\
\text { on the job" (Jenkins \& Warren, 2012, p. 391). }\end{array}$ \\
\hline & $\begin{array}{l}\text { "The physical, emotional, and mental exhaustion caused by long-term } \\
\text { involvement in emotionally demanding situations" (Jenkins \& Warren, } \\
\text { 2012, p. 391). }\end{array}$ \\
\hline & $\begin{array}{l}\text { The failure of an organization to provide support that is adequate to the } \\
\text { needs of employees (Schaufeli \& Greenglass, 2001). }\end{array}$ \\
\hline \multirow[t]{2}{*}{ Law Enforcement } & $\begin{array}{l}\text { A psychological syndrome to chronic interpersonal stressors on the job } \\
\text { that develops from an imbalance between the demands placed on indi- } \\
\text { viduals and their ability to cope that results in feelings of exhaustion, } \\
\text { cynicism, detachment, ineffectiveness, and a personal lack of accom- } \\
\text { plishment (Finney et al., 2013). }\end{array}$ \\
\hline & $\begin{array}{l}\text { A stress response that includes exhaustion, cynicism, diminished profes- } \\
\text { sional and personal efficacy (Klinoff et al., 2018). }\end{array}$ \\
\hline Social Work & $\begin{array}{l}\text { "Symptoms, including feelings of hopelessness, that are related to diffi- } \\
\text { culties in dealing with work or managing one's job effectively" } \\
\text { (Thomas, 2013, p. 372). }\end{array}$ \\
\hline Education & $\begin{array}{l}\text { The negative attitudes experienced from the exhaustion of emotional } \\
\text { resources and lack of personal achievements (Savas et al., 2014). }\end{array}$ \\
\hline Athletics & $\begin{array}{l}\text { A period of staleness and slumps experienced from physical and emo- } \\
\text { tional exhaustion, poor performance, and depersonalization (Akhrem \& } \\
\text { Gazdowska, 2016). }\end{array}$ \\
\hline
\end{tabular}

Table 2 shows that across nursing practice, definitions of compassion fatigue are similar, with the nurse's loss of self in caregiving as a major focus. Additionally, Table 2 shows that in other disciplines (social workers, mental health workers, lawyers, and family caregivers) compassion fatigue has been used in association with individuals that are susceptible to witnessing adverse events that may affect their ability to care for others (Adams, Boscarino, \& Figley, 2006; Burnett, 2017; Cocker \& Joss, 2016; Jenkins \& Warren, 2012; Norton, Johnson, \& Woods, 2016; Thieleman \& Cacciatore, 2014; Thomas, 2013).

\section{Results}

\section{Critical Attributes}

Critical attributes are the variables required for a concept to exist and are intended to facilitate a distinction between concepts (Walker \& Avant, 2011). Table 3 identifies the critical attributes of burnout and compassion fatigue. Each attribute is discussed separately in the following discussion to provide clarity to their role within each respective concept.

Stress. The role of stress is a critical attribute to both burnout and compassion fatigue as both concepts arise from chronic activations of stress responses in the body. Stress is the shifting in homeostasis that occurs in response to physical or psychological stimuli (Goodnite, 2014; Laukhuf \& Laukhuf, 2016). When exposed to stress, the sympathetic nervous system releases hormones that include catecholamines and glucocorticoids (Laukhuf \& Laukhuf, 2016). Initially, this hormonal release serves as a compensation mechanism within the body to help an individual overcome a perceived state of instability within their environment. However, the repeated activation of this process is not healthy as these hormones increase respiratory rate, heart rate, and blood pressure which eventually tires and wears the body out (Laukhuf \& Laukhuf, 2016 ). Since glucocorticoids also serve a role in helping the 
TABLE 2. Definitions of Compassion Fatigue

\begin{tabular}{|c|c|}
\hline Source & Definition \\
\hline $\begin{array}{l}\text { Classical Definition (derived from the field of } \\
\text { Psychology) }\end{array}$ & $\begin{array}{l}\text { A feeling of biological, psychological, and social exhaustion caused by } \\
\text { prolonged exposure to compassionate stress (Figley, 1995). }\end{array}$ \\
\hline \multirow[t]{4}{*}{ Nursing } & The loss of a nurse's ability to nurture their patients (Joinson, 1992). \\
\hline & $\begin{array}{l}\text { The stress obtained from the progressive and cumulative therapeutic } \\
\text { use of oneself to continuously provide patient care (Coetzee \& Klopper, } \\
\text { 2010). }\end{array}$ \\
\hline & $\begin{array}{l}\text { The nurse's inability to love, nurture, care for, or empathize with } \\
\text { another's suffering as a result of prolonged physical, emotional, and } \\
\text { spiritual self-sacrifices in care delivery (Harris \& Griffin, 2015). }\end{array}$ \\
\hline & $\begin{array}{l}\text { The repeated activation of empathic and sympathetic responses to pain } \\
\text { and distress in patients and their loved ones that deplete or exhaust } \\
\text { compassionate stores in nurses (Pembroke, 2015). }\end{array}$ \\
\hline Social Work & $\begin{array}{l}\text { The repeated exposure to trauma that reduces the empathetic ability of } \\
\text { others (Adams et al., 2006; Thieleman \& Cacciatore, 2014; Thomas, 2013) }\end{array}$ \\
\hline Mental Health Workers & $\begin{array}{l}\text { The "reduced capacity for empathy as manifested through emotional, } \\
\text { behavioral, physical, spiritual, interpersonal, and cognitive reactions } \\
\text { experienced by a disaster mental health service provider or any individ- } \\
\text { ual helping a traumatized person" (Burnett, 2017, p. 1). }\end{array}$ \\
\hline Lawyers & $\begin{array}{l}\text { "The cumulative emotional, psychological and physical effects of expo- } \\
\text { sure to the pain, distress or injustice suffered by clients" (Norton et al., } \\
2016, \text { p. 988). }\end{array}$ \\
\hline Family Caregivers & $\begin{array}{l}\text { A "condition experienced by caregivers who provide daily care to seri- } \\
\text { ously ill or dying family members and are simultaneously exposed to } \\
\text { the patient's pain while experiencing their own emotional pain" (Lynch } \\
\text { \& Lobo, 2012, p. 2128). }\end{array}$ \\
\hline
\end{tabular}

TABLE 3. Definitions of Critical Attributes of Burnout and Compassion Fatigue

\section{Burnout}

Stress

Exhaustion
The shifting in homeostasis that occurs in response to physical or psychological stimuli (Goodnite, 2014; Laukhuf \& Laukhuf, 2016).

An extension of one's self, either mentally or physically, that leaves an individual worn out or tired (Lee et al., 2016).
The shifting in homeostasis that occurs in response to physical or psychological stimuli (Goodnite, 2014; Laukhuf \& Laukhuf, 2016). With compassion fatigue, stress is a result of the nurse-patient relationship (Lachman, 2016).

Exhaustion The feeling that an individual has nothing more to give. With compassion fatigue, exhaustion results from an individual's continual giving of self and presents when an individual's biological, psychological, and social resources have been depleted (Figley, 1995).

Ineffective Coping An individual's inability to cope despite the coping mechanisms utilized.

Lack of Empathy
The loss of ability to relate to patients and their associated thoughts, feelings, and experiences (Lynch \& Lobo, 2012). 
body to maintain immunity, repeated exposure to stress also reduces the body's ability to fight infection; making individuals more susceptible to illnesses (Laukhuf \& Laukhuf, 2016).

In high-stakes environments, the stress associated with burnout is the result of the demands of the work environment. Nurses in these settings have reported having inadequate support, or the feasibility of accessing support, from employers, managers, and peers as a continuous stressor within the workplace (Wahlberg, Nirenberg, \& Capezuti, 2016). Despite the lack of support, nurses are still expected to manage a workload that includes extensive problem solving, multitasking, and critical thinking due to the increased acuity levels of their patients (Al-Majid et al., 2018; Ko \& Kiser-Larson, 2016). Nurses' workload consistently elicits activation of the body's stress response, which in turn increases the incidence or potential to experience burnout as the body tires from persistent exposure to work-related stressors.

The stress experienced with compassion fatigue results from secondary traumatic stress, which is a type of emotional stress. Secondary traumatic stress results from memories of a traumatic event that influences an individual's desire to help relieve suffering (Jenkins \& Warren, 2012). For example, memories from a patient dying in pain is a traumatic event that influences how a nurse compassionately cares for a patient in a similar situation. The constant recall of this traumatic event activates the nurses' stress response and results in compassion fatigue as the individual becomes weary in their emotions, thoughts, and feelings; similar to the process seen in posttraumatic stress disorder (PTSD), where a traumatic event is the trigger of an individual's stress response (Sorenson, Bolick, Wright, \& Hamilton, 2016).

Exhaustion. Like stress, exhaustion is also an attribute of both burnout and compassion fatigue, but the degree experienced varies with each concept. With burnout, exhaustion can be physical, emotional, or both. It occurs when there has been an overextension of self that leaves an individual worn out or tired (Lee et al., 2016). Exhaustion associated with burnout is often resolved by removing stressors through periods of rest, changes in environment, or behavior. Ultimately, with burnout, exhaustion feels like an individual has participated in a strenuous workout and needs to rest to catch their breath.
With compassion fatigue, exhaustion is the feeling that an individual has "nothing more to give." It results from an individual's continual giving of self and presents when an individual's biological, psychological, and social resources have been depleted (Figley, 1995); even after attempts to replenish have occurred. With compassion fatigue, the feeling of exhaustion is draining and leaves the individual with a sense of emptiness. There is a desire to rest but the individual does not feel a sense of recharge or energy after doing so; such as a battery that does not hold a charge no matter how long it is left on a charger.

Ineffective Coping. Ineffective coping is a critical attribute of compassion fatigue and occurs when an individual is unable to cope despite the coping mechanisms utilized. The ability to cope is essential for nurses. When coping is ineffective, nurses no longer have the tools needed to manage the stress and exhaustion of providing patient care, which leaves them with an inability to restore themselves from a depleted state. Rebounding from this state of depletion is difficult because nurses with compassion fatigue are often attempting to cope using approaches that have previously been successful for them. For this reason, multiple approaches such as self-care practices, renewal strategies, and colleague support are often needed to help nurses overcome compassion fatigue states (Potter, Deshields, Berger et al., 2013; Potter et al., 2013).

Lack of Empathy. A lack of empathy is an additional critical attribute of compassion fatigue. Lynch and Lobo (2012) argued that a loss of empathy occurs as part of a shift in which one is attempting to manage the stress of caregiving. During this shift, nurses lose their ability to empathize; their sensitivity to the patient's needs is lost and they do not understand or place themselves within the context of the patient's feelings, thoughts, and perspectives (Lynch \& Lobo, 2012). As a result, they experience compassion fatigue because patient experiences are no longer relatable (Lynch \& Lobo, 2012).

\section{Antecedents}

Antecedents are events or incidents that take place before individuals experience an associated concept (Walker \& Avant, 2011). They are important to the understanding of a concept because they clarify critical attributes by framing the context in which a concept is experienced (Walker \& Avant, 
2011). Antecedents of burnout and compassion fatigue are based on factors from the workplace and patient experiences.

With burnout, antecedents are workplace driven (Harris \& Griffin, 2015). Typically, a nurse in a state of burnout is dissatisfied with some condition of the workplace which they have failed to influence or change (Ahola, Toppinen-Tanner, \& Seppänen, 2017; Guveli et al., 2015). This may include a lack of organizational or managerial support, high workloads, role conflicts, and perceived unfairness in the workplace (Ahola et al., 2017; Guveli et al., 2015). As nurses fail at influencing these stressors, they experience increased feelings of anxiety, depression, frustration, and exhaustion. Over time, these factors cause nurses to experience breaks in their persistence. Although high-stakes environments are stressful, persistence is necessary for the nurse's success as it provides momentum; or the push that keeps nurses going despite how they feel (Jenkins \& Warren, 2012). When nurses have a break in their persistence, they feel the need to be recharged or to seek a period of rest and thus experience burnout.

The antecedents of compassion fatigue are patient-centered. Typically, a nurse with compassion fatigue has experienced repeated exposure to direct observation of patient's fear, pain, and suffering during which time they have developed an intimate nurse-patient relationship (Boyle, 2011; Lee et al., 2012). This causes the nurse to experience a large degree of emotional trauma (Jenkins \& Warren, 2012) that leads to stress (secondary traumatic stress).

Interestingly, burnout is also an antecedent of compassion fatigue. Although burnout is relieved with periods of rest, over time there is a tendency to physically and emotionally deplete nurses' coping reserves when instances of burnout are continuously experienced. An indication of this is when nurses begin to demonstrate neurotic behavior (You, Huang, Wang, \& Bao, 2015). Neurotic behavior includes being overly emotional, anxious, hypersensitive, worried, moody, or depressed (You et al., 2015). These traits contribute to passive coping strategies, with individuals coping away from a stressor instead of toward the stressor (You et al., 2015). When individuals cope passively, they experience less efficiency and accomplishment, which leads to their lack of energy to directly confront stressors head on (You et al., 2015). When this happens, compassion fatigue results.

\section{Consequences}

Consequences are outcomes that occur as a result of a concept being experienced (Walker \& Avant, 2011). Although there are similarities in the consequences of burnout and compassion fatigue, there are also some noted differences. With compassion fatigue, the consequences are the result of unresolved elements of burnout that present with greater intensity. The effects on the occupational health and well-being of nurses provides a good illustration. Nurses with burnout experienced depression, insomnia, and decreased libido, which contributed to tiredness and lack of energy (Guveli et al., 2015; Lee et al., 2016). Likewise, nurses with compassion fatigue experienced physical and mental fatigue, but often to the degree of weight gain/loss (Jenkins \& Warren, 2012; Perry, Toffner, Merrick, \& Dalton, 2011). Nurses with burnout also developed negative outlooks, mostly toward work situations, that decreased interpersonal communication and led to challenges with maintaining positive relationships with others (Guveli et al., 2015). The same effect is also seen with compassion fatigue, but challenges with communication extended into relationships in one's personal life and included emotional breakdowns (Jenkins \& Warren, 2012; Perry et al., 2011).

Both burnout and compassion fatigue result in workplace imbalances (Perry et al., 2011; Potter et al., 2013). Turnover rates in high-stakes environments are among the most notable (Rushton et al., 2015). Turnover results when nurses began to seek other work opportunities to eliminate the stress of the workplace. As turnover rates increase, the stress in the workplace intensifies as nurses begin to adjust to staffing shortages, which subsequently adds to the experience of burnout. Turnover also contributes to low job satisfaction, which with compassion fatigue, was a driving cause for a nurse's consideration of leaving the profession (Perry et al., 2011; Potter et al., 2013).

Depersonalization is another consequence of both burnout and compassion fatigue. Depersonalization occurs when nurses lack human feelings or emotions in how they provide care, which results in substandard care (Jenkins \& Warren, 2012). With burnout, depersonalization often presents as a coping mechanism used to manage exhaustion (Lee et al., 2016) and is not from a standpoint of lacking empathy for the patient. Nurses with depersonalization due to burnout often become "robotic" and focus on moving from task to task, or patient to patient, to "hurry up and 
finish." With compassion fatigue, the severity of depersonalization is to the degree that nurses view patients as "objects" (Lee et al., 2016). An example of this would be when the patient goes from being referred to as "Ms. Johnson" to "the patient in room 501."

The ultimate consequence of burnout and compassion fatigue is poor patient outcomes. When nurses were experiencing burnout and compassion fatigue, patients experienced decreased quality of care (Guveli et al., 2015; McHugh, Kutney-Lee, Cimiotti, Sloane, \& Aiken, 2011), as they were more prone to adverse events from nursing errors (Jenkins \& Warren, 2012; Ledoux, 2015; Perry et al., 2011; Rushton et al., 2015). McHugh et al. (2011) argued that burnout rates among nurses in hospitals contributed to the decline in recommendations of the same facility by patients to their friends and family, as assessed through the Hospital Consumer Assessment of Healthcare Providers and Systems (HCAHPS). This finding suggests that patients can sense the stress of the working environment through the care received. As patients tend to rely on nurses to alleviate the stress of their disease (Boyle, 2011; Lee et al., 2012), these feelings may inadvertently cause patients to question if their care is ideal and in turn result in additional patient stress. Additionally, patient dissatisfaction with care can influence the Medicare and Medicaid reimbursements hospitals receive if patients continuously return negative HCAHPS scores (Hinderer et al., 2014). Therefore, it is in the best interest of hospitals to address both burnout and compassion fatigue in nurses to prevent potential financial and other losses.

\section{Empirical Referents}

Walker and Avant (2011) noted empirical referents as ways in which a concept can be measured. Empirical referents are summarized in Table 4 for both concepts.

Burnout. The Oldenburg Burnout Inventory, Rescue Worker Burnout Questionnaire, and Copenhagen Burnout Inventory are some of the instruments which have been utilized to measure burnout. However, it is the Maslach Burnout Inventory (MBI) that is the most commonly used tool across disciplines (Guveli et al., 2015; Lee et al., 2016; Rushton et al., 2015). The MBI is a 22item assessment that uses a 7-point Likert scale to assess burnout through three subscales: emotional exhaustion, depersonalization, and personal accomplishment. It has demonstrated validity and reliability (Maslach et al., 1996). The higher an individual's score on the MBI, the greater the degree of burnout (Maslach et al., 1996). On average, medical professionals have normative subscales scores of approximately 22 for emotional exhaustion (range $=0-54$ ), seven for depersonalization (range $=0-30)$, and 37 for personal accomplishment (range $=0-48$; Rushton et al., 2015).

Compassion Fatigue. A major problem with tools used to assess compassion fatigue is the limitation of addressing multiple variables associated with the phenomenon (Sabery et al., 2017). For instance, several instruments such as the MBI, Oldenburg Burnout Inventory, Copenhagen Burnout Inventory, Impact of Event Scale, Connor-Davis Resilience Scale, and Ways of Coping Questionnaire have been used in compassion fatigue research although they only measure a single aspect of compassion fatigue; mainly burnout or stress (Cieslak et al., 2014; Potter et al., 2013). Interventions that collectively targeted multiple compassion fatigue variables were found most effective in reducing compassion fatigue in nurses (Cocker \& Joss, 2016; Houck, 2014; Potter, Deshields, Berger et al., 2013; Potter et al., 2013; Sorenson et al., 2016; Weidlich \& Ugarriza, 2015).

The Professional Quality of Life Scale (ProQOL; Stamm, 2010) is one instrument that evaluates multiple compassion fatigue variables: increased burnout, secondary traumatic stress, and reduced compassion satisfaction. However, these variables are independent subscales and are not totaled to formulate a compassion fatigue composite score (Stamm, 2010). This creates a limitation in utilizing this tool for research. An alternative instrument, The Nurses' Compassion Fatigue Inventory (NCFI; Sabery et al., 2017), offers a more robust assessment of compassion fatigue. The NCFI is a 35-item assessment that uses a five-point Likert scale ranging from one (never) to five (always). All 35 items are added together to form a composite compassion fatigue score, which can range from 35 to 175. The higher the composite compassion fatigue score, the more severe an individual's level of compassion fatigue (Sabery et al., 2017). Sabery et al. (2017) further break scores down by three classifications: low (scores ranging from 35 to 81.6), moderate (scores ranging from 81.6 to 128.2) to high (128.2-175). The Cronbach's alpha for the instrument is $\alpha=.94$. The tool was validated by Sabery et al. (2017) through exploratory factor analysis and revealed a six-factor model that 
TABLE 4. Empirical Referents of Burnout and Compassion Fatigue

\begin{tabular}{|c|c|c|c|}
\hline Instrument & $\begin{array}{l}\text { Concept(s) } \\
\text { Measured }\end{array}$ & $\begin{array}{l}\text { Definition of Burnout and/or } \\
\text { Compassion Fatigue }\end{array}$ & Subscales \\
\hline $\begin{array}{l}\text { MBI Versions: } \\
\text { - MBI-Human Services Sur- } \\
\text { vey } \\
\text { - } \text { MBI-Human Services Sur- } \\
\text { vey for Medical Personnel } \\
\text { - MBI-Educators Survey } \\
\text { - MBI-General Survey } \\
\text { - MBI-General Survey for } \\
\text { Students }\end{array}$ & Burnout & $\begin{array}{l}\text { Burnout is a syndrome that } \\
\text { includes emotional exhaustion, } \\
\text { depersonalization, and a lack } \\
\text { of personal accomplishments } \\
\text { (Maslach \& Jackson, 1981; } \\
\text { Maslach, Jackson, \& Leiter, } \\
\text { 1996). }\end{array}$ & $\begin{array}{l}\text { Subscales for the Human Ser- } \\
\text { vices Survey, Human Services } \\
\text { Survey for Medical Personnel, } \\
\text { and Educator Survey } \\
\text { versions: } \\
\text { - Emotional exhaustion } \\
\text { - Depersonalization } \\
\text { - Personal accomplishment } \\
\text { Subscales for the General Sur- } \\
\text { vey and General Survey for } \\
\text { Students versions: } \\
\text { - Exhaustion } \\
\text { - Cynicism } \\
\text { - Professional efficacy }\end{array}$ \\
\hline Oldenburg Burnout Inventory & Burnout & $\begin{array}{l}\text { Burnout is exhaustion and an } \\
\text { individual's level of disengage- } \\
\text { ment from work (Demerouti, } \\
\text { Bakker, Vardakou, \& Kantas, } \\
\text { 2003). }\end{array}$ & $\begin{array}{l}\text { - Exhaustion } \\
\text { - Disengagement }\end{array}$ \\
\hline Copenhagen Burnout Inventory & Burnout & $\begin{array}{l}\text { Burnout is physical and psy- } \\
\text { chological fatigue and exhaus- } \\
\text { tion (Kristensen, Borritz, Villad- } \\
\text { sen, \& Christensen, 2005). }\end{array}$ & $\begin{array}{l}\text { - Personal burnout } \\
\text { - Work-related burnout } \\
\text { - Client-related burnout }\end{array}$ \\
\hline ProQOL & $\begin{array}{l}\text { Compassion Satis- } \\
\text { faction } \\
\text { Compassion Fatigue } \\
\text { (determined from } \\
\text { burnout and sec- } \\
\text { ondary traumatic } \\
\text { stress) }\end{array}$ & $\begin{array}{l}\text { Burnout is the associated feel- } \\
\text { ings of hopelessness and diffi- } \\
\text { culties in dealing with work or } \\
\text { in doing one's job effectively } \\
\text { (Stamm, 2010). } \\
\text { Compassion fatigue is the neg- } \\
\text { ative aspect of helping those } \\
\text { who experience traumatic } \\
\text { stress and suffering and can } \\
\text { include elements of burnout } \\
\text { and secondary traumatic stress } \\
\text { (Stamm, 2010). }\end{array}$ & $\begin{array}{l}\text { - Burnout } \\
\text { - Secondary traumatic stress } \\
\text { - Compassion satisfaction }\end{array}$ \\
\hline $\begin{array}{l}\text { Nurses' Compassion Fatigue } \\
\text { Inventory }\end{array}$ & Compassion Fatigue & $\begin{array}{l}\text { Compassion fatigue is an occu- } \\
\text { pational hazard of clinical prac- } \\
\text { tice that places a caregiver in } \\
\text { a state of extreme fatigue and } \\
\text { undermines their ability and } \\
\text { desire to tolerate the agony of } \\
\text { others (Sabery, Tafreshi, Hos- } \\
\text { seini, Mohtashami, \& Ebadi, } \\
\text { 2017). }\end{array}$ & $\begin{array}{l}\text { - Limited personal capabili- } \\
\text { ties } \\
\text { - Caring infirmity } \\
\text { - Psychosomatic disorders } \\
\text { - Emotional fatigue } \\
\text { - Social isolation } \\
\text { - Incompetence in self and } \\
\text { family management }\end{array}$ \\
\hline Impact of Event Scale & $\begin{array}{l}\text { Distress for any spe- } \\
\text { cific life event }\end{array}$ & $\begin{array}{l}\text { Burnout and/or compassion } \\
\text { fatigue not assessed }\end{array}$ & $\begin{array}{l}\text { - Avoidance } \\
\text { - Intrusions }\end{array}$ \\
\hline Impact of Event Scale-Revised & $\begin{array}{l}\text { Distress for any spe- } \\
\text { cific life event }\end{array}$ & $\begin{array}{l}\text { Burnout and/or compassion } \\
\text { fatigue not assessed }\end{array}$ & $\begin{array}{l}\text { - Avoidance } \\
\text { - Intrusions } \\
\text { - Hyperarousal }\end{array}$ \\
\hline
\end{tabular}

(Continued) 
TABLE 4. Empirical Referents of Burnout and Compassion Fatigue (Continued)

\begin{tabular}{|c|c|c|c|}
\hline Instrument & $\begin{array}{l}\text { Concept(s) } \\
\text { Measured }\end{array}$ & $\begin{array}{l}\text { Definition of Burnout and/or } \\
\text { Compassion Fatigue }\end{array}$ & Subscales \\
\hline Connor-Davis Resilience Scale & Resilience & $\begin{array}{l}\text { Burnout and/or compassion } \\
\text { Fatigue not assessed }\end{array}$ & No subscales \\
\hline Ways of Coping Questionnaire & Coping processes & $\begin{array}{l}\text { Burnout and/or compassion } \\
\text { fatigue not assessed }\end{array}$ & $\begin{array}{l}\text { - Confrontive coping } \\
\text { - Distancing } \\
\text { - Self-controlling } \\
\text { - Seeking social support } \\
\text { - Accepting responsibility } \\
\text { - Escape-avoidance } \\
\text { - Planful problem solving } \\
\text { - Positive reappraisal }\end{array}$ \\
\hline
\end{tabular}

Note MBI = Maslach Burnout Inventory; ProQOL = Professional Quality of Life Scale.

explained $66.24 \%$ of the total variance of compassion fatigue. These six factors included limited personal capabilities, caring infirmity, psychosomatic disorders, emotional fatigue, social isolation, and incompetence in self and family management. For these reasons, the NCFI empiric referent would be essential to any initiative or study focused on influencing compassion fatigue outcomes.

\section{Synthesized Definition}

After careful analysis, consideration of literary findings, and with respect to all multidisciplinary aspects, synthesized definitions of both burnout and compassion fatigue are derived to support an understanding among nurses caring for patients in high-stakes environments. Burnout is the experience of physical or mental exhaustion nurses feel from prolonged workplace stress for which coping helps to resolve. Compassion fatigue is the experience of physical or mental exhaustion that arises from patient care in which the nurse is left drained, without empathy, and unable to effectively cope.

\section{Constructed Cases}

\section{Burnout}

Model Case. Nurse A works on an inpatient oncology unit. Her unit includes a mixture of patients such as chemotherapy admissions, postoperative patients, and patients experiencing treatment/ disease-related complications. On average, Nurse A has five patients each shift.
Over the last 6 months, the hospital administration decided to designate Nurse A's unit as an overflow area for patients from two other units. Many nurses, including Nurse A, are not happy about this change. Several of the nurses resigned which has now left the unit understaffed. Due to her skill set and expertise, Nurse A is assigned to take on a sixth patient during some shifts, as well as help precept new staff as they are hired.

As time has passed, Nurse A feels continuously tired at the end of her shift (exhaustion). She moves continuously from the time she clocks in till the time she clocks out. Many shifts she skips her lunch break just to ensure she can leave work on time. Knowing that her shifts are intense (stressful), Nurse A sleeps in longer on her days off and goes to the spa for a massage. Although this recharges her to start her next shift, she mentally anticipates the tired feeling she will experience when she goes back to work. However, she knows her patients need her. She goes back to work ready to give them her best effort.

Contrary Case. Nurse B works on the same inpatient oncology unit as Nurse A. She also has been asked to take on an extra patient and precept new staff. She also leaves the hospital at the end of each shift feeling tired (fatigue); but as if she has had a good workout at the gym. She feels her shifts are intense (busy), but to the degree where she feels continuously occupied but not rushed or pressured. She is consistently able to take her lunch and break periods and uses this time to relax and regroup. She prepares for her shifts by getting adequate rest on her days off and returns to work restored and ready to make a difference with her next group of patients. 


\section{Compassion Fatigue}

Model Case. Nurse C works on an inpatient oncology unit where oncology patients are routinely admitted for chemotherapy and treatment associated complications. As a result, Nurse C sees patients throughout their treatment and has a rapport with many. While delivering care, she frequently engages with patients as they express their care experiences including fear of death, pain, nausea, and other side effects of treatment.

Over the last few weeks, Nurse $C$ has left the hospital after her shift with feelings that she is stretched thin both mentally and physically (exhaustion). She has lost several close patients throughout her last few shifts. She constantly worries (stress) about how their loved ones are doing. She frequently has thoughts of "what is it now" when call lights go off. She has lost her ability to connect with patients. She provides patient care "on the surface," handling only those concerns that cannot wait till the next shift. She neglects the emotional needs of her patients (lack of empathy), often leaving out of the room in a hurry when patients attempt to confide in her because she does not want to hear another sad story. She has attempted to meditate to relieve her stress but finds this only results in her staring into space and becoming increasingly frustrated (ineffective coping).

Contrary Case. Nurse D works on the same oncology unit as Nurse C. Over the last few weeks, she too has left the hospital at the end of her shift feeling "stretched thin" (exhaustion). She spends her shift addressing the emotional concerns of her patients, including sitting with the family of a patient that died mid-shift (empathy). To alleviate the stress of the day, she meditates over a warm bubble bath when she gets home and finds meaning in the care she delivered (effective coping). She wakes up the next morning feeling recharged and ready to take on the next group of patients.

\section{Discussion}

Caring for patients in high-stakes environments can be difficult for nurses who are experiencing burnout or compassion fatigue. The ability to recognize both concepts is pivotal in helping nurses to establish strategies that help them cope and achieve optimal occupational health. This concept analysis has discussed several distinctions between the two concepts that can be used in this regard. Perhaps the most significant is the identifi- cation of burnout as an antecedent of compassion fatigue. This aspect is important because burnout was found to be modifiable through periods of rest, changes in environment, or behavior, giving it the potential to be resolved with the removal of stressors. In addition, burnout is often a result of conflicts between employer-employee relationships and not conflicts in the nurse-patient relationship (Harris \& Griffin, 2015; Ledoux, 2015). Therefore, if one could address and manage burnout appropriately, it could reduce the chance that a nurse develops compassion fatigue and result in better occupational health.

There are also several elements of burnout and compassion fatigue that overlap. This concept analysis has noted that in the areas of overlap, the severity differs. For instance, stress and exhaustion are critical attributes of both concepts. However, with burnout, stress and exhaustion result in the nurse being in a tired state; with compassion fatigue, the result is that a nurse is in a drained state. As the intensity of stress and exhaustion experienced in the workplace could be a contributor to both concepts, research should focus on interventions that help nurses manage their stress (Ahola et al., 2017; Lee et al., 2016). Effectively coping with workplace stress has the potential to influence workplace sustainability; positively impacting both burnout and compassion fatigue through a reduction in turnover rates and improved job satisfaction. As one's satisfaction helps to determine their outlook toward the stress experienced in high-stakes environments, understanding this phenomenon will help to identify specific strategies nurses need to overcome burnout. It will also help to bring an understanding of how burnout develops into the associated concept of compassion fatigue.

Caring for high-stakes patients involves a large degree of empathy because of the potential lifethreatening outcomes these patients are at risk of experiencing. This analysis identified a lack of empathy as one of the differences between compassion fatigue and burnout. Yet, a deeper understanding of empathy is needed concerning what influences nurses to lose this ability among highstakes patients. Studies using qualitative methods could help to provide this understanding.

\section{Conclusion}

This concept analysis has conceptually differentiated between the concepts of burnout and 
compassion fatigue in the context of high-stakes environments and discussed their relevance as two distinct concepts in nursing practice. From this analysis, nurses can identify burnout and compassion fatigue in both themselves and their colleagues, as well as develop appropriate interventions to support their coping efforts. Understanding burnout and compassion fatigue are key in helping nurses to achieve optimal occupational health. Thus, the definitions of burnout and compassion fatigue in this analysis serve to enhance conceptual understanding, reasoning, and encourage communication among nursing staff caring for patients in high-stakes environments.

\section{References}

Adams, R. E., Boscarino, J. A., \& Figley, C. R. (2006). Compassion fatigue and psychological distress among social workers: A validation study. American Journal of Orthopsychiatry, 76, 103-108. https://doi.org/10.1037/00029432.76.1.103

Ahola, K., Toppinen-Tanner, S., \& Seppänen, J. (2017). Interventions to alleviate burnout symptoms and to support return to work among employees with burnout: Systematic review and meta-analysis. Burnout Research, 4, 1-11. https://doi.org/10.1016/j.burn.2017.02.001

Akhrem, A., \& Gazdowska, Z. (2016). Analysis of the athlete burnout phenomenon: The past the present and the future of athlete burnout research. Baltic Journal of Health $\mathcal{E}$ Physical Activity, 8(3), 60-70. doi: 10.29359/BJHPA.08.3.07

Al-Majid, S., Carlson, N., Kiyohara, M., Faith, M., \& Rakovski, C. (2018). Assessing the degree of compassion satisfaction and compassion fatigue among critical care, oncology, and charge nurses. Journal of Nursing Administration, 48, 310315. https://doi.org/10.1097/NNA.0000000000000620

Boyle, D. A. (2011). Countering compassion fatigue: A requisite nursing agenda. Online Journal of Issues in Nursing, 16(1), 2. https:/ / doi.org/10.3912/OJIN.Vol16No01Man02

Burnett, H. J. (2017). Revisiting the compassion fatigue, burnout, compassion satisfaction, and resilience connection among CISM responders. SAGE Open, 7(3), 1-10. doi: $10.1177 / 2158244017730857$

Cieslak, R., Shoji, K., Douglas, A., Melville, E., Luszczynska, A., \& Benight, C. C. (2014). A meta-analysis of the relationship between job burnout and secondary traumatic stress among workers with indirect exposure to trauma. Psychological Services, 11, 75-86. https://doi.org/10.1037/ a0033798

Cocker, F., \& Joss, N. (2016). Compassion fatigue among healthcare, emergency and community service workers: A systematic review. International Journal of Environmental Research and Public Health, 13(6), 618. https://doi.org/ 10.3390/ijerph13060618
Coetzee, S. K., \& Klopper, H. C. (2010). Compassion fatigue within nursing practice: A concept analysis. Nursing and Health Sciences, 12, 235-243. https://doi.org/ 10.1111/j.1442-2018.2010.00526.x

Demerouti, E., Bakker, A. B., Vardakou, I., \& Kantas, A. (2003). The convergent validity of two burnout instruments: A multitrait-multimethod analysis. European Journal of Psychological Assessment, 19, 12-23. Retrieved from https://psycnet.apa.org/doi/10.1027//1015-5759. 19.1.12

Figley, C. (1995). Epilogue: The transmission of trauma. In C. Figley (Ed.), Compassion fatigue: Coping with secondary traumatic stress disorder in those who treat the traumatized (pp. 248-254). London, United Kingdom: Brunner-Routledge.

Finney, C., Stergiopoulos, E., Hensel, J., Bonato, S., \& Dewa, C. S. (2013). Organizational stressors associated with job stress and burnout in correctional officers: A systematic review. BMC Public Health, 13, 82. doi: 10.1186/1471-2458-13-82

Freudenberger, H. (1974). Staff burnout. Journal of Social Issues, 30(1), 159-165. doi: 10.1111/j.1540-4560.1974.tb00706.x

Goodnite, P. M. (2014). Stress: A concept analysis. Nursing Forum, 49, 71-74. https:/ / doi.org/10.1111/nuf.12044

Guveli, H., Anuk, D., Oflaz, S., Guveli, M. E., Yildirim, N. K., Ozkan, M., \& Ozkan, S. (2015). Oncology staff: Burnout, job satisfaction and coping with stress. Psycho-Oncology, 24, 926-931. https:/ / doi.org/10.1002/pon.3743

Harris, C., \& Griffin, M. T. (2015). Nursing on empty: Compassion fatigue signs, symptoms, and system interventions. Journal of Christian Nursing, 32, 80-87. https://doi.org/ 10.1097/CNJ.0000000000000155

Hinderer, K. A., VonRueden, K. T., Friedmann, E., McQuillan, K. A., Gilmore, R., Kramer, B., \& Murray, M. (2014). Burnout, compassion fatigue, compassion satisfaction, and secondary traumatic stress in trauma nurses. Journal of Trauma Nursing, 21, 160-169. https://doi.org/ 10.1097/JTN.0000000000000055

Houck, D. (2014). Helping nurses cope with grief and compassion fatigue: An educational intervention. Clinical Journal of Oncology Nursing, 18, 454-458. https://doi.org/ 10.1188/14.CJON.454-458

Jenkins, B., \& Warren, N. A. (2012). Concept analysis: Compassion fatigue and effects upon critical care nurses. Critical Care Nurse Quarterly, 35, 388-395. https:/ / doi.org/ 10.1097/CNQ.0b013e318268fe09

Joinson, C. (1992). Coping with compassion fatigue. Nursing, 22, 116-122.

Klinoff, V. A., Van Hasselt, V. B., Black, R. A., Masias, E. V., \& Couwels, J. (2018). The assessment of resilience and burnout in correctional officers. Criminal Justice and Behavior, 45, 1213-1233. https://doi.org/ $10.1177 / 0093854818778719$

Ko, W., \& Kiser-Larson, N. (2016). Stress levels of nurses in oncology outpatient units. Clinical Journal of Oncology Nursing, 20, 158-164. https://doi.org/ 10.1188/16.CJON.158-164

Kristensen, T. S., Borritz, M., Villadsen, E., \& Christensen, K. B. (2005). The Copenhagen burnout inventory: A new tool 
for the assessment of burnout. Work \& Stress, 19, 192-207. https:/ / doi.org/10.1080/02678370500297720

Lachman, V. D. (2016). Ethics, law, and policy. Compassion fatigue as a threat to ethical practice: Identification, personal and workplace prevention/management strategies. MEDSURG Nursing, 25, 275-278.

Laukhuf, R. L., \& Laukhuf, G. A. (2016). Stress in radiology nursing. Journal of Radiology Nursing, 35, 205-210. https:/ / doi.org/10.1016/j.jradnu.2016.02.005

Ledoux, K. (2015). Understanding compassion fatigue: Understanding compassion. Journal of Advanced Nursing, 71, 2041-2050. https://doi.org/10.1111/jan.12686

Lee, H., Kuo, C., Chien, T., \& Wang, Y. (2016). A metaanalysis of the effects of coping strategies on reducing nurse burnout. Applied Nursing Research, 31, 100-110. https://doi.org/10.1016/j.apnr.2016.01.001

Lee, M., Laurenson, M., \& Whitfield, C. (2012). Can compassion be taught to lessen the effects of compassion fatigue? Journal of Care Services Management, 6, 121-130. https://doi.org/10.1179/1750168713Y.0000000016

Lynch, S. H., \& Lobo, M. L. (2012). Compassion fatigue in family caregivers: A Wilsonian concept analysis. Journal of Advanced Nursing, 68, 2125-2134. https:// doi.org/10.1111/j.1365-2648.2012.05985.x

Maslach, C., \& Jackson, S. E. (1981). The measurement of experienced burnout. Journal of Occupational Behavior , 2, 99-113. https:/ / doi.org/10.1002/job.4030020205

Maslach, C., Jackson, S., \& Leiter, M. (1996). Maslach burnout inventory manual (3rd ed.). Palo Alto, CA: Consulting PsychologistsPress.

McHugh, M. D., Kutney-Lee, A., Cimiotti, J. P., Sloane, D. M., \& Aiken, L. H. (2011). Nurses' widespread job dissatisfaction, burnout, and frustration with health benefits signal problems for patient care. Health Affairs, 30, 202-210. https:/ / doi.org/10.1377/hlthaff.2010.0100

Norton, L., Johnson, J., \& Woods, G. (2016). Burnout and compassion fatigue: What lawyers need to know. UMKC Law Review, 84, 987-1002.

Pembroke, N. (2015). Contributions from Christian ethics and Buddhist philosophy to the management of compassion fatigue in nurses. Nursing and Health Sciences, 18, 120-124. https://doi.org/10.1111/nhs.12252

Perry, B., Toffner, G., Merrick, T., \& Dalton, J. (2011). An exploration of the experience of compassion fatigue in clinical oncology nurses. Canadian Oncology Nursing Journal, 21, 91-105. https:/ / doi.org/10.5737/1181912x2129197

Potter, P., Deshields, T., Berger, J. A., Clarke, M., Olsen, S., \& Chen, L. (2013). Evaluation of a compassion fatigue resiliency program for oncology nurses. Oncology Nursing Forum, 40, 180-187. https://doi.org/10.1188/13.ONF. 180-187

Potter, P., Deshields, T., \& Rodriguez, S. (2013). Developing a systemic program for compassion fatigue. Nursing Administration Quarterly, 37, 326-332. https://doi.org/ 10.1097/NAQ.0b013e3182a2f9dd

Rushton, C. H., Batcheller, J., Schroeder, K., \& Donohue, P. (2015). Burnout and resilience among nurses practicing in high-intensity settings. American Journal of Critical Care, 24, 412-420. https: / / doi.org/10.4037/ajcc2015291

Sabery, M., Tafreshi, M., Hosseini, M., Mohtashami, J., \& Ebadi, A. (2017). Development and psychometric evaluation of the nurses' compassion fatigue inventory. Journal of Nursing Measurement, 25, E185-E201. http:/ /dx.doi.org/10.1891/1061-3749.25.3.E185

Savas, A. C., Bozgeyik, Y., \& Eser, I. (2014). A study on the relationship between teacher self-efficacy and burnout. European Journal of Educational Research, 3, 159166. https://doi.org/10.12973/eu-jer.3.4.159

Schaufeli, W., \& Greenglass, E. (2001). Introduction to special issue on burnout and health. Psychology and Health, 16, 501510. https:/ / doi.org/10.1080/08870440108405523

Sorenson, C., Bolick, B., Wright, K., \& Hamilton, R. (2016). Understanding compassion fatigue in healthcare providers: A review of current literature. Journal of Nursing Scholarship, 48, 456-465. https://doi.org/10.1111/ jnu.12229

Stamm, B. H. (2010). The concise ProQOL manual (2nd ed.). Pocatello, ID: ProQOL.org.

Sullivan, C. E., King, A., Holdiness, J., Durrell, J., Roberts, K., Spencer, C., . . . Mandrell, B. (2019). Reducing compassion fatigue in inpatient pediatric oncology nurses. Oncology Nursing Forum, 46, 338-347. https:// doi.org/10.1188/19.ONF.338-347

Thieleman, K., \& Cacciatore, J. (2014). Witness to suffering: Mindfulness and compassion fatigue among traumatic bereavement volunteers and professionals. Social Work, 59, 34-41. https://doi.org/10.1093/sw/swt044

Thomas, J. (2013). Association of personal distress with burnout, compassion fatigue, and compassion satisfaction among clinical social workers. Journal of Social Service Research, 39, 365-379. https://doi.org/10.1080/ 01488376.2013 .771596

Villani, D., Grassi, A., Cognetta, C., Toniolo, D., Cipresso, P., \& Riva, G. (2013). Self-help stress management training through mobile phones: An experience with oncology nurses. Psychological Services, 10, 315-322. https://doi.org/10.1037/a0026459

Wahlberg, L., Nirenberg, A., \& Capezuti, E. (2016). Distress and coping self-efficacy in inpatient oncology nurses. Oncology Nursing Forum, 43, 738-746. https:// doi.org/10.1188/16.ONF.738-746

Walker, L. O., \& Avant, K. C. (2011). Strategies for theory construction in nursing (5th ed.). Upper Saddle Ridge, NJ: Pearson/Prentiss-Hall.

Weidlich, C. P., \& Ugarriza, D. N. (2015). A pilot study examining the impact of care provider support program on resiliency, coping, and compassion fatigue in military health care providers. Military Medicine, 180, 290-295. https:/ /doi.org/10.7205/MILMED-D-14-00216

Wentzel, D. L., \& Brysiewicz, P. (2018). A survey of compassion satisfaction, burnout and compassion fatigue in nurses practicing in three oncology departments in Durban, South Africa. International Journal of Africa Nursing Sciences, 8, 82-86. https:/ / doi.org/10.1016/j.ijans.2018.03.004 
You, X., Huang, J., Wang, Y., \& Bao, X. (2015). Relationships between individual-level factors and burnout: A meta-analysis of Chinese participants. Personality and Individual Differences, 74, 139-145. https://doi.org/ 10.1016/j.paid.2014.09.048

Disclosure. The author(s) have no relevant financial interest or affiliations with any commercial interests related to the subjects discussed within this article.

Acknowledgments. The author wishes to acknowledge Ellen Fineout-Overholt, PhD, RN, FNAP, FAAN; Danita
Alfred, PhD, RN; and E'Loria Simon-Campbell, PhD, RN for their guidance and encouragement in writing this manuscript.

Funding. The author received no specific grant or financial support for the research, authorship, and/or publication of this article.

Correspondence regarding this article should be directed to Franklin Wynn, $\mathrm{PhD}(\mathrm{c}), \mathrm{MSN}, \mathrm{RN}, \mathrm{CNE}, \mathrm{OCN}$, The University of Texas at Tyler, Tyler, Texas, USA. E-mail: frankjwynn@swbell.net 